\title{
Using multicultural narratives to explore loss and grief
}

This chapter will explore literacy development of refugee and asylum seeker children from a range of ethnic groups who may have experienced loss and grief due to various reasons and how we can support them both in their own and their new cultural settings. Types of losses experienced by primary aged children will be discussed and how they might appear to cope with them. There will be a discussion about how through the use of multicultural literature teachers in primary schools can help such children deal with the pain of loss and grief along with rebuilding their lives in the new culture. Finally a framework for working with a chosen few multicultural texts will be shared. Milton (2004) defines a loss as when anything that is valued or anyone we are attached to is removed from our lives. Grief is the process by which we adjust to living with a significant loss - it is the pain of 'letting go'. In the context of refugee and asylum seeker children, this loss can be compounded due to the extreme confusion or urgency with which they might find their circumstances changed or changing.

\section{Introduction: Who are refugee children?}

'Refugee children are ordinary children in extraordinary circumstances' (Hope, 2008).

UNHCR's founding mandate defines refugees as people who are outside their country and cannot return owing to a well-founded fear of persecution because of their race, religion, nationality, political opinion, or membership of a particular social group. When people flee their own country and seek sanctuary in another state, they often have to apply for "asylum" - the right to be recognized as bona fide refugees and receive legal protection and material assistance. Studies (VölklKernstock . et.al, 2014) have revealed that often the most vulnerable war victims, children, are at increased risk of developing mental health problems if not supported appropriately, in addition to lack of formal school education which many children in the western world may take it as a given.

\section{Loss and grief in childhood experienced in migration (forced or otherwise):}

Refugee and asylum seeker children often experience the loss of people, places, pets and possessions throughout their lives as the dependants of migrant parents or carers (although some children have become unaccompanied minors as well; Völkl-Kernstock . et.al, 2014). Gilbert (2008) has coined the term Third Culture Kids (TCKs) for children who accompany their parents to live all or part of their childhood outside the country for which they hold a passport (Pollock \& Van Reken, 1999; Useem, 1993). This term might equally apply to asylum-seeking and refugee children who are currently in the primary schools in the UK. As many of them have had to leave their countries of birth without prior warning or consent, often there is a sense of loss and grief involved with this sudden loss of normalcy. This is very commonly reported as a lingering concern among adult TCKs, that is, adults who were TCKs as children (Barringer, 2000; Cockburn, 2002; Pollock \& Van Reken, 1999; Schaetti, 2002). Many of the attributes that particularly characterize TCKs - prolonged adolescence, feelings of rootlessness, alienation, and inability to make commitments (Barringer, 2000) - can be tied to unresolved grief issues (Schaetti, 2002). This is where schools have an important part to play in creating safe and normal spaces where children can process their grief and rebuild their lives with renewed enthusiasm and hope for the future. Primary school teachers are in 
an ideal situation to support children who may be experiencing loss and grief due to circumstances beyond their control and to prepare all children for future (eventual) experiences of loss.

Before going any further, it is important to address the unique characteristics of children's grief that may complicate the ability of adults to recognize and respond to the needs of such children. In general, grief centres around the process of making sense of a loss, regardless of the age and developmental stage of the individual (Silverman, 2000). Each child makes sense of a loss in the context of his or her developmental stage and related capabilities (Oltjenbruns, 2007; Silverman, 2000), and the child may "regrieve" the loss as he or she moves through new developmental stages and has a new appreciation for what exactly was lost especially if the situation in their own homeland (in case of refugee children) is changing on a day to day basis for a prolonged period (Oltjenbruns, 2001).

Children's grief often does not look like adult grief (Oltjenbruns, 2007; Sekar\& Katz, 1986), and adults (teachers and carers) may not recognize that the child is grieving. In the classroom, on a day to day basis, children may appear to lack feelings about the loss, but it may be that they feel overwhelmed by their grief and shut down emotionally in response (Wolfert, 1983). Adults may minimize the seriousness of the loss, or they may ignore or disparage the child's response (Crenshaw, 2002), thus marginalizing the grief experience of the child. On the other hand, parents/carers and teachers may recognize the child's grief, and may try to protect children from the pain of loss by encouraging them to focus on the positive or by keeping them away from the experiences that serve as reminders of the loss. The result may be that the children feel isolated in what may seem to be overwhelming and unnerving emotions (Oltjenbruns, 2001). Such feelings, if unresolved, can affect the future development of refugee children. Those that have an immediate complicating effect are the fact that losses often are hidden, and being hidden, are not acknowledged; they experience a lack of permission to grieve and a lack of time to process the loss; finally, a lack of comfort maybe offered to the children as they attempt to deal with their losses. Although individual situations and stories may vary for refugee children, they may feel a sense of responsibility toward their parents/carers and may hide their feelings from adults (Pollock \& Van Reken, 1999). They may deny and/or suppress emotions related to loss, potentially leading to later complications (Oltjenbruns, 2007). Many of the losses experienced, particularly those that are hidden, are ambiguous. 'Ambiguous losses' are those that lack clarity and can lead to sharply different assessments of exactly who or what has been lost (Boss, 2004 in Gilbert, 2008). Often the children are too young to make sense of what exactly happened before they left home (city or country of birth). With uncertainty or lack of awareness about how to respond, teachers in the classroom may respond in a way that does not meet the needs of the griever (Gilbert, 1996). This, combined with a lack of knowledge about the nature of children's grief, increases the likelihood that children will not receive the support they need, thus complicating their grief.

The grief experienced by refugee children clearly has characteristics of disenfranchised grief (Doka, 2002; Schaetti, 2002). Their socially ambiguous losses may not be openly mourned or socially supported. Essentially, this is grief that is restricted by "grieving rules" ascribed by the new culture and society in which they may find themselves piecing their lives together on a day to day basis. Often refugee children may change schools as they may move from one local authority to another. It may be further compounded by the grief that results from the loss of trust in the availability of 
adults to be sensitive to their emotions. Losses that are not successfully resolved in childhood have an increased likelihood of recurring in adulthood. Thus, how losses and the resulting grief are dealt with continue to influence the lives of refugee children into adulthood (Gilbert, 2008).

Before we discuss different types of losses and griefs any further, let's see what it might look like in a typical primary classroom:

\section{Case Study:}

Noor is seven years old and managed to escape from Syria where the civil war has been raging for some time. He came to the UK with his mother and a younger brother, Salim, aged five along with some other extended family members. Noor's elder brother was killed in the bombing in Aleppo, which Noor had witnessed. Naturally, he is traumatised by this event. His father stayed behind to find a safe passage for Noor's grandparents. Due to the unrest it is very difficult for his father to stay in touch and inform regularly about his well-being. This causes a lot of anxiety for Noor's mother which Noor shares as well. None of the family members who came to England speak any English; their native language is Arabic. Noor and his younger brother attend local schools, but Noor attends the junior school and Salim attends the infant school. Since the schools are on separate campuses, Noor and Salim don't get to see each other.

Activity: Make a list of some of the main areas where Noor would need support.

Here are some suggestions:

- During 'Circle time', which is used in many primary schools to facilitate PSHE (personal, social, health and economic education) related issues, use the 'Seeking safety' activity booklet available for free download on https://www.amnesty.org.uk/files/activities__seeking_safety.pdf. Use this to highlight discussion around Noor's situation inviting him to contribute if he feels comfortable. It is important that you share your intentions for the activity with the child beforehand.

- Get in touch with Arabic speaking staff members if possible or involve other parents or wider community to arrange for interpretation so that the parents and refugee children know what is expected of them. Aim to collect as much information about the family as possible.

- Refugee children may be in need of psychological support before they are fully ready to concentrate on their schoolwork. Speak to the SENCO to arrange support.

- Arrange a buddy within the class with an Arabic-speaking child, if possible, to help with school routines and make friends initially.

- Offer time and support right from the start to develop a trusting relationship with the child. Gradually, if the child wishes to share, listen and acknowledge the traumatic experiences that the child has been through.

- Use children's literature to establish a shared understanding, raise awareness and stimulate discussion within the classroom. The role of multicultural literature in raising awareness will be discussed in detail later in the chapter as well. 


\section{Disenfranchised grief}

As we age, we may experience a range of losses as we make the transition to another developmental period. These losses can be profound as we move to later life, but can even be significant as we give up childhood activities and toys to embrace the responsibilities of adolescence and emerging adulthood. This takes on a new dimension in case of refugee children, who may have to suddenly grow up or take additional responsibilities due to change in circumstances. Self-disenfranchisement (Gilbert, 2008) can also be seen, particularly when it is related to a parent's/carer's financial situation or mental health in the new environment. Evidence exists to suggest that the process of grieving is more easily resolved if those grieving have the opportunity to discuss events and their feelings (Gilbert, 1996). Contrary to this, refugee children may feel comfortable growing up, not focusing on loss and keeping their feelings to themselves. In such circumstances, as well as being good listeners and good communicators, teachers need to be able to use the language of loss, grief and death easily and naturally. With multicultural classrooms, the children will be members of families with a range of different religious beliefs and cultural practices regarding loss and grief. Milton (2004) suggests that rather than be fearful of this, teachers can use this to their advantage by enlisting parental help and exploring these cultural and religious differences together thus developing more understanding of each other.

\section{Loss of persons}

Refugee children may have experienced the deaths of family members, including both in the immediate and extended family. The death of a parent is an already devastating loss, and it may compound their sense of loss, because it often results in an end to a familiar lifestyle or a move to a country that may seem alien compared to the country in which they had been living. Some children may have experienced or witnessed the deaths of friends, caregivers and other adults in their lives. Although they may not have known the individuals involved, it may be that refugee and asylumseeking children have had the experience of surviving a coup and seeing dead bodies, and, in some cases, witnessing executions. In most cases, their grief becomes disenfranchised. There may be other losses as a result of high mobility of the peer network. In the UK, The Immigration and Asylum Act 1999 introduced a policy of dispersal that compels asylum seekers to move to different parts of the country if they wish to receive support with accommodation. This means that asylum seekers' lives can be characterised by periodical displacement within the UK as a result of migration policies rather than choice (Bourgonje, 2010). Although it may be easier to make use of the Internet to stay in contact with friends, they may miss the easy, relaxed camaraderie of close physical proximity. Over time, children may learn to adapt to the loss of friends as a normal part of their life. But initially they would need support and a listening ear in order to adapt to the new cultural and educational settings.

\section{Loss of places}

Moving away from their home country or place of birth is a commonly cited loss by refugee and asylum seeking children. Often these children have the challenge of adjusting to adverse events in the past while forging important emotional, social, and intellectual developmental trajectories in a new setting (Reed et. al. 2012). The smells, tastes, cultural rituals, site-specific opportunities, in addition to the physical aspects of the country - geography and climate - are often cited as missing 
(Gilbert, 2008) in their lives, especially, if there are no warnings of an impending move. The loss becomes compounded in most extreme situations. For example, emergency evacuations because the situation has become too dangerous and potentially life-threatening. In addition to that, they can be burdened with challenges that include altered family dynamics, such as assuming the role of carer for younger siblings or psychologically and physically injured parents. Children who resettle across international borders often combine these tasks while managing a new language, education system, and culture, typically in difficult economic and legal circumstances (Eisenbruch, 1988). Leaving one school and moving to another can be a significant loss as well. In addition to struggling with a different curriculum, the change in school means the loss of support network in the form of friends and even one to one support provided by additional adults etc. linked with that place.

Lost opportunities can often be tied to specific places, either where they (refugee children) were or where they wished they were. Older children may feel the loss of exposure to culture, in the form of TV shows, museums and performance venues that may be available in their home country. This has an impact on the extent to which refugee children can be a part of the popular culture in the host country. A high degree of displacement during the younger years can manifest itself as a sense of detachment with places. In extreme situations, children may feel no intimate connection with any particular place.

\section{Case study:}

Amanullah (a refugee child from Afghanistan) enjoyed the guided reading session which involved collecting information about sandstorms and river systems in the desserts as a part of reading comprehension in year 6 . He had spent his initial years in the mountains of Afghanistan before his family was granted asylum in the UK. His eyes lit up as he shared his memories of taking shelter in the shops to avoid the sand storms in the late afternoons and later taking a dip in the nearby river. He remembered the names of all his friends who used to jump in the river with him. He was sad that he might never see them again due to the conflict in Afghanistan. However, sharing his memories and experiences with his classmates in England surely added to the development of camaraderie and social networks that children build in their schooling years.

Activity: Read the case study above and think about the following:

1. How could school help Ammanullah familiarise with popular culture in the host country?

2. How could teachers capitalise on the wider experiences of the refugee children through cross -curricular teaching and learning? Think about individual subjects that might facilitate the exchange.

\section{Loss of pets}

Grief over the loss of pets can be a source of unrest for children who may have been attached to them before leaving them behind. For those for whom pets were meaningful parts of their lives, the loss of these animals could be quite painful. This can be particularly true when animals served the role of friend or companion to the child. As a teacher, it is important to be mindful of such feelings and provide opportunities within the classroom to bring these feelings to the surface, maybe through discussions (picture books) or debates about why and how to look after pets. 


\section{Loss of possessions}

Refugee children remain at increased risk of developing mental health difficulties due to the traumatic experiences and multiple losses, which the majority of these children have suffered (Hodes, 1998; Rousseau, 1995 in Ehntholt.et.al, 2005). Amongst various losses incurred, although possessions may hold lesser meaning for adults at times of extreme conflict, personal possessions are generally precious to young children, especially, if there is a danger of having to choose what they can take when leaving home, forever, in most cases. Refugee children may be attached to a range of objects: articles of clothing, toys, books, blankets, jewellery, dishware, decorative hangings and artwork, and photographs to name a few. Hence, it is important to be mindful that from the point of view of refugee children, the institution (school, fellow classmates, other professionals) have everything - a fixed place in society, a voice, status, money, etc. - which has been lost to them (Summerfield, 2000).

\section{Existential losses}

Existential losses involve the loss of security in knowing that what they have thought of as real is actually reflective of reality (Janoff-Bulman, 1992), that is, that the world they knew up to this point as reliable and predictable will continue to be so. For refugee and asylum seeking children, this may include the belief, built over time, that relationships are fluid, nothing stays the same, and that the ability to adapt to change is highly valued in the adult world. Following a loss, meaning must be attributed in such a way as to allow the individual to regain a sense of order, control and purpose in life (Gilbert, 1996). Teachers in school can help in the process of empowerment by arranging for interventions (short and long term) which would help children regain control and power over their circumstances. Initial assessments and support structures need to take account of factors such as values and beliefs in the countries of origin, the personal cultural values of the children, the varying environments and experiences during different stages of migration, as well as the legal statuses of family members. Such information can be gathered during initial interviews with refugee families in the first few weeks of children joining school.

\section{Loss of a safe and trustworthy world}

A common belief is that children need to feel secure in their lives and their relationships in order to function and develop well (Erikson, 1963). One aspect of a secure attachment to one's assumptive world is a sense that the world is safe and trustworthy. Refugee children share the painful loss of home and separation from culture with other immigrant children. However, what is potently different in case of refugee and asylum seeking children is the assault on human psyche, loss of lives and entire social communities resulting in loss of trust and safety (Falicov, 2002).

\section{Case study:}

"I left all my friends, everyone behind! left alone here." (Abdi, a ten year old refugee child talking about his friends in school in Syria) 
Abdi's friends, who had been close, had become estranged or simply stopped corresponding and essentially disappeared from his life once he had moved to England. Although he described efforts to maintain contact especially with his elder brothers in the extended family, he also described himself as having become aloof and cautious about forming relationships in the school and the community in England. He spent most of his time helping the teachers and hardly went out to play during playtime. The most common loss that relates to safety and trust is the one related to trust in a social setting - the loss of a sense of belonging. Although this feeling of loss is more common when children make the transition from primary to secondary school, it could happen when children try to make friends in new surroundings. In addition to that, his feelings were essentially raw as his family had witnessed political coup of which he had a mixed understanding, followed by riots as a part of the disruption in his home country. He said some of his family members had seen dead bodies in the streets, and, witnessed murder. He became quite emotional in describing his fears as his parents and other extended family members attempted to do what they could to keep the families safe. He used terms like "bloody", "terrifying," and "horrible" in an attempt to describe what he had gone through.

Activity: Reading this case study, discuss the following questions:

1. How could you help Abdi rediscover the sense of normality and belonging?

2. How could you encourage Abdi to talk about his experiences with a view to encourage other children to talk about their losses as well?

\section{Loss: "Who I Thought I Was"}

If refugee children go through primary school without adequate support in developing self-esteem and social networks, there is a danger that they can experience a delayed adolescence in which they deal with the issue of identity long after one would normally expect it to be resolved (Schaetti, 2002; Useem \& Cottrell, 1996). Gilbert (2008) highlights that such children can be highly adaptable in taking on the appearance and accent of indigenous children, but missing the fine details of life of what they may see as an alien world. Here teachers and additional adults can help by building meaningful relationships with refugee children aimed at mentoring them into the dominant culture both inside and outside school.

Fontino and Colak (2001) highlight: uprooting, disruption, and insecurity as the by-products of migration affecting the psychological and social development of refugee children. This makes the process of identity formation a more difficult balancing act between two or more sets of cultural notions and values. We often hear "children adapt quickly." Perhaps we should ask: "To what? In relation to whom? At what price?"

\section{Case study:}

Abdi started primary school with a temporary asylum certificate which presented him as younger than he actually was. He had finally been granted asylum in England after living with his aunt in Ethiopia in order to save him from the civil war in Somalia. In ideal circumstances, he should have been in a secondary school, but due to some confusion with his paperwork he was offered a place in year six instead. Abdi was extremely keen to learn English and wanted to become either a pilot or a footballer. He developed a close relationship with the teaching assistant who used to work with him learning English. He often asked for additional homework and would often stay in class helping her 
out with classroom chores and practising his spoken English when other children were not around. Abdi would often speak about his formative years in Somalia and later Ethiopia where he looked after his aunt's land and shops along with his uncle. Often nostalgic, he compared his experiences in both worlds and longed to become a footballer so that he could help his country and community, just like other celebrity footballers such as Ronaldo. The teaching assistant, realizing his potential and innate desire to learn, started arranging for extra home work for maths and English so that Abdi would be better prepared for the secondary school.

Activity: Reading this case study, think about the following as a teacher:

1. How could you encourage Abdi to feel a part of the classroom community and make friends?

2. How could you value his experiences and include him in the curriculum?

3. Bolloten and Tim Spafford (1998, p. 109) state that "Raising awareness of what it means to be a refugee ... is a vital step in understanding the needs of refugee children." Discuss how that could be achieved.

\section{Loss of a place they can call home}

This loss is related to the loss of security in their personal identity. Young refugee children are often not able to verbalise their struggle through childhood to define home. So, rather than thinking of the loss of home, they relate better to the concept of experiencing grief at the recognition that home (as they knew it) is somehow absent from their lives (Gilbert, 2008). As a society we place much emphasis on the individual, making the refugee family and their history almost invisible. Refugee children become children without a history. As a result, when helpers and practitioners analyse the behaviour of a refugee child out of context, there is a tendency to 'pathologise' that behaviour (Fantino and Colak, 2001). Many ordinary cultural practices of refugee families are often misunderstood in our classrooms, hospitals, social services, and social life.

\section{Case study:}

When Noor first came to the UK, for the first few weeks at school, he did not want to speak about his home in Aleppo. Gradually he started talking a little about how his mother is worried about his father and the rest of the family. One could clearly see the nostalgia in his eyes as he spoke about his childhood days spent there without the fear of bombs dropping overhead. It was never a straight forward sentence; rather a glimpse of a rainbow as he drew a picture of a house in a reading session.

"I can jump to the terrace of my friend's house from our rooftop, Miss! You can't do that here".

He missed his elder brother who was killed in the bombing. Initially, Noor did not want to talk, draw, or remember the war, his brother, or his former home. He only wanted to draw butterflies and happy faces. Questions about the future and memories of the past were selectively put out of mind. He had nightmares that kept him terrified for days and change the expression on his face. While his mother dealt with her own illness and losses, Noor was placed in a position that seemed to overwhelm him. Between his practical duties of taking care of his younger brother, learning a new language, adapting to a new culture, and worrying about the future, he had neither the time nor 
energy to grieve. Activities and social connections outside the family were limited because of the family's recent arrival and language barriers. Since the teacher started showing genuine interest in Noor by encouraging him to talk to her about his home, Noor started expressing a sense of relief and optimism which was evident in his behaviour and progress at school.

Activity: Reading this case study, think about the following:

1. How could schools/ teachers influence the welcome that refugee children receive in the host community / country?

2. What are some of the key factors that influence the adaptation of refugee children as compared to immigrant children? Think about mental and physical trauma, mourning of losses incurred, homesickness etc.

\section{Role of multicultural literature in supporting refugee children in school}

Multicultural literature focuses on people of colour from diverse cultural, linguistic and religious groups (Canales, Lucido \& Salas, 2002 in Boles, 2006). Hefflin and Barksdale-Ladd (2001) discuss the importance of children relating to characters and situations found in books reflective of their own culture. This longing for a sense of belonging is more potent in refugee children. Here multicultural literature can provide children with a sense of affirmation about themselves and their culture (Colby \& Lyon, 2004). In the western system of education, often, children are encouraged to make personal connections with what they are reading so it is important for refugee children to be able to see themselves and situations that they can relate to. Carefully selected multicultural literature can be used to create a classroom where all children are valued (Colby \& Lyon, 2004). Since reading is so personal, teachers need to examine the literature available to students. Colby and Lyon (2004) further emphasise that children need to receive affirmation of themselves and their culture through literature (Bieger, 1995/1996), and be able to connect text to self in order to promote greater meaning (Dietrich \& Ralph, 1995; Keene \& Zimmerman, 1997; Rosenblatt, 1978).

For younger refugee children, teachers can use multicultural literature to encourage development of vocabulary, stimulating imagination, facilitating empathy, increased knowledge of one's own heritage, and fostering positive self-concepts and identity (Taylor, 1997 in Boles 2006).

Ford, Harris \& Howard (1999) identified six main goals of multicultural literature:

1. Increase in sense of self-worth and a sense that they have a chance for a successful future.

2. Achieve educational equity which has three basic conditions:

a. an equal opportunity to learn,

b. positive educational outcomes for both individuals and groups, and

c. equal physical and financial conditions for students to grow to their fullest potential cognitively, academically, and affectively.

3. Support cultural pluralism by helping children develop understanding and respect for people who are different from them.

4. Create a sense of empowerment in children so that they become independent learners and feel empowered to take an active role in improving the lives of others.

5. Work in groups in harmony by providing knowledge and skills to prepare children to work with members of their own cultural groups and other cultural groups. 
6. Teaching from a multicultural perspective challenge assumptions and stereotypes starting from the classroom. For example, teachers need to select literature that does not promote stereotypical perspectives.

Adapted from Ford, Harris \& Howard in 1999.

\section{Choosing Multicultural Literature:}

When choosing books for refugee children, it is important to make sure that the themes selected are relatable to the experiences of such children (Meier, 2003). Canales, et.al, (2002) highlight that the selected texts should represent authentic experiences portrayed in a true-to-life and balanced manner; be consistent with the values, beliefs, customs, traditions, needs and conflicts of the specific culture; be free of stereotypes in language, illustrations, behaviour, and character traits and finally the language used must show sensitivity to the culture.

Drama is a classic area where emotions such as empathy can be given maximum exposure, and the works of Day (2002) and Watts (2004) demonstrate the strengths as well as the limitations of confronting refugee issues through the medium of drama. Hope (2008) highlights that other subject areas, such as art and music can be used as backdrops for generating conversations which can empower refugee children. The links with history and geography are also clear, but also wholeschool initiatives, such as Refugee Week, can exploit the tremendous educative potential of books, giving them the context for discussion to have maximum impact. However, there is a danger of the focus being lost after the Refugee Week.

\section{Strategies for Teaching Multicultural Literature:}

Engagement with multicultural literature should be focussed on making reading fun as well as generating thoughtful insights. Meier (2003) suggests a good starting point can be teaching, book reading behaviours, explicitly by asking questions, answers for which are found directly in the text. Teachers can go further by making books come alive for refugee children through the use of props, for example, dolls and puppets to act stories out in the class. This helps children form powerful attachments to the literature (Meier, 2003).

Children in primary schools should be introduced to multicultural texts consciously instead of simply exposing them to literature. It can be argued that English lessons are the obvious vehicle for the introduction of children's literature about the refugee experience, and Habib (2008) discusses the importance of choosing class texts of contemporary relevance not only in English but other cross curricular subjects as well. Kruse (2001) proposes that introducing a text implies that you are establishing an acquaintance with that text, along with a possibility that further dialogue will ensue suggesting pleasant and sustained engagements with diversity. However, stories about refugee experiences may not always be pleasant. Hence, it requires a commitment on the part of the teachers to normalise the discourse, however unpleasant. Encouraging children to make connections with the refugee literature and apply the lessons learnt, to their everyday lives, would help to routinize the use of multicultural texts in the classroom. Finally, it is significant that teachers do not 
simply tell a story or experience but take the time to discuss what children have read, as with any good piece of literature.

\section{Examples of how teachers can use refugee literature in class through sample texts:}

In this section, we shall look at four examples of multicultural children's literature which can be used to highlight the narratives of young refugee lives. Along with the individual texts, a frame work for working with refugee literature is also shared.

Here I am by Patti Kim: This is a picture book (suitable for all ages) illustrating the trials and trepidations experienced by a young boy who arrives in a strange land where he doesn't understand the language or the customs. The weather is cold and wet and he misses his home. Gradually he begins to make new friends and finds that not everything in the new country disagreeable. He eventually settles into his new life and feels comfortable in his new home.

Some activities to explore the text:

- Make a list of what you would pack if you had just a little time? What would you miss? What would it be like to be forced to leave home suddenly?

- Create a Welcome Pack focussing on what could help make a refugee child feel more comfortable and less scared in his/her new home.

- With older children, make a collage explaining what "refugee" means -- someone who is forced to flee their home because they fear they will lose their lives or freedom if they stay.

- Together using drama, imagine arriving in a new country without knowing the language or customs. Help the children "walk in the shoes" of a refugee child by asking:

- What would it be like to have to leave home quickly and suddenly?

- What would you pack if you had just a little time? (Many refugees leave their homes with little warning and cannot even bring basic necessities.)

- What would you miss?

- How would you feel?

- What could help make a refugee feel more comfortable and less scared in their new home?

Azzi in Between by Sarah Garland: This is a thoroughly absorbing tale of a little girl called Azzi who comes in to a new country with her parents as a refugee. The excitement of coming to England is overshadowed by the sadness incurred as a result of having to leave grandma behind in the war zone. Through her incredible resourcefulness and sheer tenacity, we see Azzi not only survive but thrive in her new world. This book is suitable for both Key Stage 1 and 2.

Some activities linked with the text:

- Explore feelings from different perspectives. For example, compare 'feelings' in the story before and after the arrival of grandma using the colour, expression and body posture in the illustrations as cues. Write a diary extract from the perspective of Azzi or Grandma.

- In order to develop visual literacy - sequence the jumbled pictures from a section of the story. You can differentiate by asking children to match the illustrations to the text first. Different groups work on different parts of the story. Once finished, children present their sequences and give reasons for their decisions and predictions for the next part of the story. 
- Roleplay - prepare short dialogues to rehearse between pairs where one is Azzi and the other is the teacher in the new school. You can prepare dialogues during a guided reading sessions beforehand.

- Children can create a comic that shows the journey from their birth country to a country of their choice. Their finished work should show an understanding of shot types, colour and composition used in comics and film. In Azzi in Between particularly Sabeen's and Grandma's stories can be used as inspiration.

Oranges in No Man's Land and A little Piece of Ground by Elizabeth Laird: These two novels are suitable for Key Stage 2 as they introduce children to the desperately courageous lives of children growing up in war zones. These texts serve as a powerful medium of giving children living the western world, an opportunity to walk in the shoes of similar young children (likely to become refugees) who frantically try to live a normal life amongst the horrors of war in the cities of Beirut (Lebanon) and Ramallah (Palestine) respectively.

Oranges in No Man's Land: Ayesha is left alone to look after her two younger brothers when grandma falls ill. It's up to the bravery of little Ayesha to cross the check point, venture into the enemy territory in order to see Dr. Laila.

A little Piece of Ground: Like most 12-year-old boys, Karim, dreams of being a champion footballer. Unfortunately, his life in Ramallah is severely hampered by the presence of Israeli troops and tanks. Despite the dangers, between curfews, Karim and his friends clear a patch of wasteland to use as a football pitch and sneak off to play whenever they can, but when the soldiers return, Karim finds himself trapped and in real danger.

Some activities linked with these texts:

- Frame of Comparison can be used during guided reading to explore the texts in detail.

- Oranges in No Man's land was written in 2006. As a class focus on how the situation has changed in modern day Lebanon. Use pictures, maps and photographs to create a news report.

- When Ayesha crosses the Green Line to the other side of Beirut, Dr. Leila allows her to dine in her house. But not everyone is happy about her being there. Imagine if Ayesha came to stay with your family. Write a story that portrays Ayesha seeking refuge in your house for a day. Would she be welcome? Would she get along with all of your family? Additionally, children could focus on writing recounts from the character's perspective.

- When Ayesha crosses the green line, she ensures that she remains quiet: she knows that if her accent is heard, they'll know where she's from. Do you know anywhere else in the world (or at school) where people have been judged by their accent? Discuss how does it feel?

- A little Piece of Ground, another text by the same author can be used for further discussion and raising awareness maybe during book clubs sessions. Further information can be found at the following links:

- http://3cenglishstudies.weebly.com/uploads/1/3/7/3/13739250/a little pie ce of ground activities.pdf

- https://education4liberation.files.wordpress.com/2012/10/lpg-pack.pdf

Alpha: Abidjan to Gare Du Nord by Bessora Barroux (translated into English by Sarah Ardizzone): Alpha is a story of a young refugee who takes on the arduous journey of escaping from the horrors 
of everyday life in Abidjan (Ivory Coast) to seek a safer future in Europe. This is a powerful retelling of the horrors encountered by one refugee and how human spirit triumphs through times of extreme desperation. This book is recommended for Upper Key Stage 2 where children should be able to empathise with human suffering caused as a result of breakdown of civic society due to multiple reasons.

Examples of activities associated with this book:

- Use the following Frame for comparison in order to explore the book in depth.

- In consultation with the children, choose a language of focus and work together to prepare a book of phrases. Don't emphasise what children would like to be able to say. Instead ask them to imagine what someone newly arrived in the area would like to hear. Imagine that the refugee is the same age as the children, and has had a hard and possibly dangerous journey here.

- Focus on including emotional, practical and fun elements in the book. Children can work in groups to come up with phrases related to basic needs, entertainment and leisure, goods and services, or social opportunities. They could include questions, but also statements - of welcome, support, friendliness, concern, expressing interest, giving information and offering invitation.

- In preparing for secondary school, children in year 6 can discuss a range of situations - from someone almost destitute to someone whose main problem is social isolation. Try to end up with a mini phrase book of useful and relevant material.

\section{A framework for comparison:}

Questions about the different features of (picture) books dealing with refugee stories:

\section{Cover}

-What do you notice on the cover of the picture book?

-What are the most important features on the cover?

- What is the title of the book? What does this title mean to you?

- Has the book won any awards? Are they displayed on the cover?

- What colours dominate the cover design?

- What is in the foreground? What is in the background? What is the significance of the placement?

- Are there any visual images in the background to consider?

- What refugee clues (if any) are provided on the cover?

2. Representation of asylum seekers and refugees

- Are asylum seekers and/or refugees represented on the cover? How are they portrayed?

- Is the main character looking at you? How does this affect you?

- If the character is looking at you, what might he/she be demanding from you?

- Is the character looking away or at someone or something else? How does this affect

you?

- Is this asylum seeker or refugee character a historical figure or fictional? How do you know?

\section{Setting}

-What setting is portrayed on the cover and other illustrations? 


\begin{tabular}{|l} 
- Describe the setting in geographical terms, e.g. find its location on a map. \\
- When do you think this story is taking place? \\
- What visual and textual clues are provided on the cover, jacket, and within the authors' \\
- How is the setting important in the context of this picture book about refugees? \\
- How is colour, texture, and motif used to represent the setting of the story? \\
- Are the illustrations realistic, folk art, surreal, or impressionistic? \\
- How might the style of illustration add to the mood or theme of the book? \\
- How does the style contribute to the understanding of a refugee's experience? \\
- Do the end pages contain a visual narrative? \\
- Do the end pages contribute to the visual continuity of the picture book? \\
- End pages represent the story of refugees in any way? \\
- Hot the imat image within the story? If so, what is the significance? \\
- How does the jacket information (if any) help to establish historical background \\
- What clues are given about the historical facts (if any) and fictional aspects being \\
presented?
\end{tabular}

Adapted from Dolan, A Intercultural Education, Picture books and Refugees: Approaches for Language Teachers, CLELE journal, Volume 2, Issue 1, 2014.

\section{A word of caution for teachers:}

Whilst engaging with characters emerging from the war zones of the world, it is important to remember not to fall into the trap of reinforcing the stereotypical constructions that cast the war torn regions as a place of ultimate violence, poverty, religious oppression, and patriarchal tyranny. There is an urgent need to disrupt these generalizations, diversify thematic foci (not just war and political tyranny), and present young readers with heterogeneous characters and settings from all over the world.

\section{Conclusion}

We need to understand refugee children's traumas, journey, losses and assets with an alliancebuilding attitude or strategy of 'not knowing,' creating an openness of inquiry that allows a coconstruction of problems and building of therapeutic alliance. Through exploring various issues 
affecting refugee children's understanding of loss and grief, we offer hope and strategies to support such children in the classroom via multicultural narratives. Finally it is important to remember to assure children that they are safe, and focus on positive ways to make a difference rather than on despair.

Word count: 7,483

\section{References:}

Barringer, C. F. (2000). Counseling third culture kids. Paper presented at the Annual Conference of the American Counseling Association, San Antonio, TX). [On-line]. Available: http://www.eric.ed.gov ERIC \#: ED451459.

Boles, M. "The Effects of Multicultural Literature in the Classroom" (2006). Senior Honors Theses. 62. http://commons.emich.edu/honors/62

Bolloten, Bill and Spafford, Tim. (1998). Supporting Refugee Children in East London Primary Schools. In Jill Rutter and Crispin Jones (Eds.), Refugee Education: Mapping the Field. Staffordshire: Trentham.

Boss, P. (2004). Ambiguous loss. In F. Wash \&M. McGoldrick (Eds.), Living beyond loss: Death in the family (2nd ed.) (pp. 237-246), New York: Norton.

Bourgonje, P. (2010). Education for refugee and asylum seeking children in OECD countries Case studies from Australia, Spain, Sweden and the United Kingdom. Education International, Belgium, ISBN 978-92-95089-44-0 (paperback)

Bieger, E. M. (1995/1996). Promoting multicultural education through a literature-based approach. The Reading Teacher 49(4), 308-312.

Canales, J., Lucido, F. \& Salas, R.G. (2002). Multicultural Literature: Broadening Young Children's Experiences. Texas.

Cockburn, L. (2002). Children and young people living in changing worlds: The process of assessing and understanding the 'Third Culture Kid.' School Psychology International, 23, 475-485.

Colby, S. \& Lyon, A. (2004). “Heightening Awareness about the Importance of Using Multicultural Literature" by Susan Colby and Anna Lyon in Multicultural Education, Spring 2004, pp. 24-28.

Crenshaw, D. A. (2002). The disenfranchised grief of children. In K. J. Doka (Ed.) Disenfranchised grief: New directions, challenges, and strategies for practice (pp. 293-306). Champaign, IL: Research Press.

Day, L. (2002). 'Putting Yourself in Other People's Shoes': The Use of Forum Theatre to Explore Refugee and Homeless Issues in Schools. Journal of Moral Education, 31, 21-34.

Dietrich, D. \& Ralph, K. S. (1995). Crossing borders: Multicultural literature in the classroom. The Journal of Educational Issues of Language Minority Students, 15, Winter. 
Doka, K. J. (2002). Introduction. In K.J. Doka (Ed.) Disenfranchised grief: New directions, challenges, and strategies for practice (pp. 5-22). Champaign, IL: Research Press.

Dolan, A Intercultural Education, Picture books and Refugees: Approaches for Language Teachers, CLELE journal, Volume 2, Issue 1, 2014.

Ehntholt K, Smith, P. \& Yule, W. (2005) School-based Cognitive-Behavioural Therapy Group Intervention for Refugee Children who have Experienced War-related Trauma. Clinical Child Psychology and Psychiatry SAGE Publications Vol 10(2): 235-250.

Eisenbruch M. (1988) The Mental Health of Refugee Children and Their Cultural Development. The International Migration Review, Vol. 22, No. 2, pp. 282-300.

Erikson, E. H. (1963). Childhood and society (2nd ed.). New York: W. W. Norton.

Falicov, C. (2002) 'Foreword', in Therapeutic Care for Refugees: No Place Like Home. London, H. KARNAC (Books) LTD. pp. xv

Ford, D.Y., Harris, J.J. \& Howard, T.C. (1999). Using Multicultural Literature in Gifted Education Classrooms. Gifted Child Today, 14-21.

Fontino, A and Colak, A. (2001). Refugee Children in Canada: Searching for Identity. Child Welfare, VoL LXXX, \#5, pp. 587-596

Gilbert, K. (2008) Loss and grief between and among cultures: the experience of third culture kids. Illness, Crisis \& Loss, Vol. 16(2) 93-109.

Gilbert, K. R. (1996). "We've had the same loss, why don't we have the same grief?" Loss and differential grief in families. Death Studies, 20, 269-283.

Habib, S. (2008). Refugee Boy: The Social and Emotional Impact of the Shared Experience of a Contemporary Class Novel. Changing English, Vol. 15, pp. 41-52.

Hefflin, B. R., \& Barksdale-Ladd, M. A. (2001). African American children's literature that helps students find themselves: Selection guidelines for grades K-3. The Reading Teacher 54(8), 810-881.

Hodes, M. (1998). Refugee children. British Medical Journal, 316, 793-794.

Hope, J. (2008). "One Day We Had to Run": The Development of the Refugee Identity in Children's Literature and its Function in Education. Children's Literature in Education, Vol. 39, pp. 295-304.

Janoff-Bulman, R. (1992). Shattered assumptions: Towards a new psychology of trauma. New York: Free Press.

Keene, E. O. \& Zimmerman, S. (1997). Mosaic of thought. Portsmouth, NH: Heinemann.

Kruse, M. (2001). Escaping Ethnic Encapsulation: The Role of Multicultural Children's Literature. The Delta Gamma Bulletin, 26-32.

Meier, T. (2003). "Why Can't She Remember That?" The importance of Storybook Reading in Multilingual, Multicultural Classrooms. The Reading Teacher, 242- 252. 
Milton, J. (2004) Helping primary school children manage loss and grief: Ways the classroom teacher can help, Education and Health Vol. 22 No.4, pp 58-60.

Oltjenbruns, K. A. (2001). Developmental context of childhood: Grief and regrief phenomenon. In M. S. Stroebe, R. O. Hanson, W. Strobe, \& H. Schut (Eds.) Handbook of bereavement research: Consequences, coping, and caring (pp. 169-197). Washington, DC: American Psychological Association.

Oltjenbruns, K. A. (2007). Life span issues and loss, grief, and mourning part 1: The importance of a developmental context: Childhood and adolescence as an example. In D. Balk, C. Wogrin, G. Thornton, \& D. Megher (Eds.) Handbook of thanatology: The essential body of knowledge for the study of death, dying, and bereavement (pp. 143-150). Northbrook, IL: The Association for Death Education and Counseling, The Thanatology Association.

Parkes, C. M. (1972). Bereavement: Studies of grief in adult life. New York: International University Press.

Pollock, D.C., \& Van Reken, R. (1999). Third culture kids: The experience of growing up among world. Yarmouth, ME: Intercultural Press.

Reed, R., Fazel, M., Jones, L., Panter-Brick, C., Stein, A. (2012) Mental health of displaced and refugee children resettled in low-income and middle-income countries: risk and protective factors. Lancet. Vol. 379, pp 250-65.

Rosenblatt, L. M. (1978). The reader, the text, the poem: The transactional theory of the literary work. Carbondale, IL: Southern Illinois University Press.

Rousseau, C. (1995). The mental health of refugee children. Transcultural Psychiatric Review, 32, 299-331.

Schaetti, B. F. (2002). Attachment theory: A view into the global nomad experience. In M. G. Ender (Ed.), Military brats and other global nomads Growing up in organization families (pp. 103-119). Westport, CT: Praeger Publishers.

Sekar, C. \& Katz, S. (1986). On the concept of mourning in childhood. Psychiatric Study of the Child, $41,287-314$.

Silverman, P. R. (2000). Never too young to know: Death in children's lives. New York, NY: Oxford University Press.

Summerfield, D. (2000). Childhood,War, Refugeedom and 'Trauma': Three Core Questions for Mental Health Professionals. Transcultural Psychiatry Vol 37(3): 417-433

Taylor, G.S. (1997). Multicultural Literature Preferences of Low-Ability African American and Hispanic American Fifth Graders. Reading Improvement, 37-48.

Useem, R. (January, 1993). Third culture kids: Focus of major study. Newslinks, XII(3). [On-line].

Useem, R. H., \& Cottrell, A. B. (1996). Adult third culture kids. In C. D.Smith (Ed.) Strangers at home (pp. 22-35). Bayside, NY: Aletheia. 
Völkl-Kernstock, S., Karnik, N., Mitterer-Asadi, M., Granditsch, E., Steiner, H., Friedrich, M., Huemer, J. (2014) Responses to conflict, family loss and flight: posttraumatic stress disorder among unaccompanied refugee minors from Africa. Neuropsychiatr Vol. 28, pp. 6-11

Wolfert, A. (1983). Helping children cope with grief, Bristol, PA: Accelerated Development.

Watts, M. (2004). Telling Tales of Torture: Repositioning Young Adults' Views of Asylum Seekers. Cambridge Journal of Education, 34, 315-329.

\section{Bibliography:}

Here I am by Patti Kim. Published 2015 by Picture Window Books.

ISBN 1479519316 (ISBN13: 9781479519316$)$

Azzi in Between by Sarah Garland. Published 2012 by Frances Lincoln Children's Bks ISBN 1847802613 (ISBN13: 9781847802613$)$

Oranges in No Man's Land by Elizabeth Laird. Published 2006 by MacMillan Children's Books ISBN 0330450271 (ISBN13: 9780330450270$)$

A little Piece of Ground by Elizabeth Laird. Published October 1st 2006 by Haymarket Books ISBN 1931859388 (ISBN13: 9781931859387$)$

Alpha: Abidjan to Gare Du Nord by Bessora Barroux (translated into English by Sarah Ardizzone). Published 2014 by Gallimard BD ASIN B00SBARVVC 